\title{
Phenothiazines and Selenocompounds: A Potential Novel Combination Therapy of Multidrug Resistant Cancer
}

\author{
MÁRIÓ GAJDÁCS ${ }^{1,2}$, MÁRTA NOVÉ ${ }^{1}$, ÁKOS CSONKA ${ }^{1,3}$, BORISZ VARGA $^{1,4}$, CARMEN SANMARTÍN $^{5,6}$, \\ ENRIQUE DOMÍNGUEZ-ÁLVAREZ ${ }^{7 *}$ and GABRIELLA SPENGLER ${ }^{1 *}$ \\ ${ }^{1}$ Department of Medical Microbiology and Immunobiology, \\ Faculty of Medicine, University of Szeged, Szeged, Hungary; \\ ${ }^{2}$ Department of Pharmacodynamics and Biopharmacy, \\ Faculty of Pharmacy, University of Szeged, Szeged, Hungary; \\ ${ }^{3}$ Department of Traumatology, Faculty of Medicine, University of Szeged, Szeged, Hungary; \\ ${ }^{4}$ Department of Rheumatology and Immunology, Szeged, Hungary; \\ ${ }^{5}$ Department of Organic and Pharmaceutical Chemistry, School of \\ Pharmacy and Nutrition, University of Navarra, Pamplona, Spain; \\ ${ }^{6}$ Instituto de Investigación Sanitaria de Navarra (IdiSNA), Pamplona, Spain; \\ ${ }^{7}$ Instituto de Química Orgánica General, Consejo Superior de \\ Investigaciones Científicas (IQOG-CSIC), Madrid, Spain
}

\begin{abstract}
Background/Aim: Phenothiazines constitute a versatile family of compounds in terms of biological activity, which have also gained a considerable attention in cancer research. Materials and Methods: Three phenothiazines (promethazine, chlorpromazine and thioridazine) have been tested in combination with 11 active selenocompounds against MDR (ABCB1-overexpressing) mouse T-lymphoma cells to investigate their activity as combination chemotherapy and as antitumor adjuvants in vitro with a checkerboard combination assay. Results: Seven selenocompounds showed toxicity on mouse embryonic fibroblasts, while three showed selectivity towards tumor cells. Two compounds showed synergism with all tested phenothiazines in low concentration ranges (1.46-11.25 $\mu \mathrm{M})$. Thioridazine was the most potent among the three phenothiazines. Conclusion: Phenothiazines belonging to different generations showed different levels of adjuvant activities. All the tested phenothiazines are already approved medicines with known pharmacological and toxicity profiles,
\end{abstract}

\footnotetext{
*These Authors contributed equally to this work.

Correspondence to: Gabriella Spengler, Ph.D., Department of Medical Microbiology and Immunobiology, Faculty of Medicine, University of Szeged, Szeged, Hungary. E-mail: spengler.gabriella@med.uszeged.hu
}

Key Words: Cancer, multidrug resistance, T-lymphoma, phenothiazines, selenoesters, selenoanhydride, combination chemotherapy. therefore, their use as adjuvants in cancer may be considered as a potential drug repurposing strategy.

Phenothiazines constitute a versatile family of compounds in terms of biological activity: though they were widely used, the interest towards these agents grew tremendously after promethazine (an antihistaminic agent) and chlorpromazine (an antipsychotic drug) were discovered in the 1940s (1). Since then, a wide variety of related compounds have been discovered and used in psychiatric patients, but recent studies indicate that these drugs could be also utilized in the treatment of other disorders, such as neurodegenerative diseases, tumors, and infections (2). Phenothiazines can inhibit efflux pumps causing multidrug resistance (MDR) (3). This inhibition is suggested by the observation that phenothiazines used as adjuvants in antibiotic therapy can re-sensitize resistant bacteria to certain antibiotics (3). Other studies have also shown that phenothiazines have a direct antibacterial effect, especially against MDR Mycobacterium tuberculosis infections, which is a pathogen of considerable morbidity and mortality (4).

Phenothiazines have also gained considerable attention in the field of cancer research (5). Their antitumor activity is exerted through different biological mechanisms, including the aforementioned MDR efflux pump inhibition (5). Several in vitro studies show that thioridazine can effectively inhibit P-glycoprotein (or ABCB1), therefore reversing resistance to cancer chemotherapy. This inhibition of MDR efflux pumps enables the reduction of the dosage for chemotherapy drugs without reducing their therapeutic effect, thus reducing their 
side effects $(2,5)$. Besides, phenothiazines - especially thioridazine and trifluoperazine - can exert antitumor activity due to their capacity to trigger apoptosis through different mechanisms, e.g., the inhibition of DNA protein kinases and DNA repair $(6,7)$, and inhibition of the binding of calcium to $\mathrm{Ca}^{2+}$-dependent enzymes (8).

Selenium and selenocompounds (Se-compounds) have crucial roles in pivotal biological processes, and there is a growing body of evidence of the potential applications of organoselenium compounds as potent chemopreventive, antiproliferative and cytotoxic drugs $(9,10)$. Moreover, Secompounds (Se-compounds) as sodium selenite and selenocystine have the ability to enhance the anticancer effects exerted by chemotherapy drugs currently used in clinical practice, such as cisplatin and doxorubicin, respectively $(11,12)$. In line with these findings, our group synthesized a series of 30 selenoesters and one cyclic selenoanhydride with marked antiproliferative and/or cytotoxic activity in selected prostate (PC-3), breast (MCF7), lung (A549) and colon (HT-29) cancer cell lines. These compounds also showed potent chemopreventive activity (13). In subsequent studies, 10 selenoesters and 1 selenoanhydride of the abovementioned $31 \mathrm{Se}$-compounds were selected for performing a more-in-depth evaluation. Our results showed that they have: (i) a potent cytotoxic activity (even in submicromolar concentrations) in human colon adenocarcinoma and breast cancer cell lines, (ii) capacity to inhibit the ABCB1 efflux pump overexpressed in MDR sublines of these colon / breast cancer cell lines with higher potency than known reference inhibitors like verapamil or thioridazine, and (iii) the ability to trigger apoptosis $(14,15)$.

Based on these promising results, in the present study, three phenothiazines (namely promethazine, chlorpromazine and thioridazine) were combined with these 11 active Secompounds against MDR mouse T-lymphoma cells to investigate their activity in combination with chemotherapy and as antitumor adjuvants in vitro. In addition, the toxicity of the tested compounds and phenothiazines was studied in non-cancerous NIH/3T3 mouse embryonic fibroblast cells.

\section{Materials and Methods}

Cell lines. $\mathrm{pHa}$ MDR1/A retrovirus was used to transfect L5178Y mouse T-cell lymphoma cells (PAR; parental cell line) (ECACC Cat. No. 87111908, acquired from the Food and Drug Administration, Silver Spring, MD, USA) as formerly described by Cornwell et al. (16). The ABCB1-expressing cell line L5178Y (MDR; multidrug resistant) was selected by culturing the infected cells with colchicine. The L5178Y human ABCB1-transfected subline was cultured in McCoy's 5A medium (Sigma-Aldrich, St Louis, MO, USA) supplemented with $10 \%$ heat-inactivated horse serum (Sigma-Aldrich), $200 \mathrm{mM}$ L-glutamine (Sigma-Aldrich) and a penicillin-streptomycin (Sigma-Aldrich) mixture at concentrations of $100 \mathrm{U} / \mathrm{l}$ and $10 \mathrm{mg} / \mathrm{l}$, respectively.
The NIH/3T3 mouse embryonic fibroblast cell line (ATCC CRL1658) was acquired from LGC Promochem, (Teddington, UK). The cell line was cultured in Dulbecco's Modified Eagle's Medium (DMEM, containing $4.5 \mathrm{~g} / 1$ glucose) supplemented with $10 \%$ heatinactivated fetal bovine serum and a penicillin-streptomycin (SigmaAldrich) mixture at concentrations of $100 \mathrm{U} / 1$ and $10 \mathrm{mg} / \mathrm{l}$, respectively. All cell lines were incubated at $37^{\circ} \mathrm{C}$, in a $5 \% \mathrm{CO}_{2}$, 95\% air atmosphere.

Compounds. Re-synthesis, purification and characterization of cyclic selenoanhydride (1) and the ten selenoesters 2-11 included in our study (Figure 1) were performed as described previously (13). All tested compounds were pure and chemically stable on air, according to the spectroscopic (IR, MS, ${ }^{1} \mathrm{H}-$ and ${ }^{13} \mathrm{C}-\mathrm{NMR}$ ) and the elemental analysis performed to confirm the structures of the different derivatives as reported previously (13). Additionally, four reference compounds 12-15 were obtained from the following providers: potassium selenocyanate $(\mathrm{KSeCN})$ and phthalic anhydride (15 and 12, respectively; Sigma-Aldrich, Seelze, Germany), potassium cyanate (KOCN, 13, Chempur, Piekary Śląskie, Poland), ammonium thiocyanate $\left(\mathrm{NH}_{4} \mathrm{SCN}, \mathbf{1 4}\right.$, Polskie Odczynniki Chemiczne, Gliwice, Poland) (Figure 1) (14). Compounds were dissolved in DMSO to obtain stock solutions. Working solutions were prepared by dilution in water, keeping the concentration of DMSO below $1 \%$ in all the experiments

The remaining chemicals used in the study were purchased from Sigma-Aldrich, (St Louis, MO, USA). These were: promethazine (PMZ), chlorpromazine (CPZ), thioridazine (TZ), 3-(4,5dimethylthiazol-2-yl)-2,5-diphenyltetrazolium bromide (MTT), sodium dodecyl sulphate (SDS) and dimethyl sulfoxide (DMSO) (Figure 2). All solutions were prepared on the day of the assay.

Assay for cytotoxic effect. The effects of increasing concentrations of the phenothiazines alone on cell growth were tested in 96-well microtiter plates. The parental and multidrug resistant mouse Tlymphoma cells were cultured using McCoy's 5A medium supplemented with $10 \%$ heat-inactivated horse serum. The density of the cells was adjusted to $1 \times 10^{4}$ cells per well (in $100 \mu \mathrm{l}$ of medium per well) and then added to the 96-well flat-bottomed microtiter plates containing the dilutions of the tested Secompounds. The cells were incubated at $37^{\circ} \mathrm{C}$, in a $5 \% \mathrm{CO}_{2}, 95 \%$ air atmosphere. The cytotoxic activity of the Se-compounds was previously determined on parental and multidrug resistant mouse Tlymphoma cells (17).

The adherent mouse embryonic fibroblast cells were cultured in 96-well flat-bottomed microtiter plates in DMEM supplemented with $10 \%$ heat-inactivated fetal bovine serum. The cells were incubated at $37^{\circ} \mathrm{C}$, in a $5 \% \mathrm{CO}_{2}, 95 \%$ air atmosphere. In a separate plate, the respective dilutions of the tested compounds were prepared. The density of the cells was adjusted to $1 \times 10^{4}$ cells per well and the cells were seeded for $4 \mathrm{~h}$ at $37^{\circ} \mathrm{C}, 5 \% \mathrm{CO}_{2}$. Then, the medium was removed and the cells were incubated with the various compounds at $37^{\circ} \mathrm{C}$ for $24 \mathrm{~h}$. At the end of the incubation period, $20 \mu \mathrm{l}$ of MTT solution (from a stock solution of $5 \mathrm{mg} / \mathrm{mL}$ ) were added to each well. After incubation at $37^{\circ} \mathrm{C}$ for $4 \mathrm{~h}, 100 \mu \mathrm{l}$ of sodium dodecyl sulfate (SDS) (Sigma) solution (10\% in $0.01 \mathrm{M}$ $\mathrm{HCI})$ were added to each well and the plates were further incubated at $37^{\circ} \mathrm{C}$ overnight $(14,15,18)$. Cell growth was determined by measuring the optical density (OD) at 540/630 nm with Multiscan 
<smiles>[Y4][Y4](=O)O</smiles>

Selenoesters
Symmetric Selenodiesters

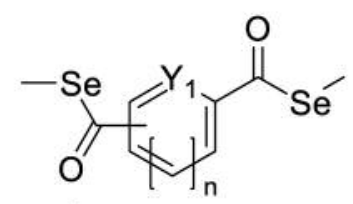

$2 \mathrm{Y}^{1}=\mathrm{S}, \mathrm{n}=0$, subst. 2,5

$3 \mathrm{Y}^{1}=\mathrm{N}, \mathrm{n}=1$, subst. 2,6

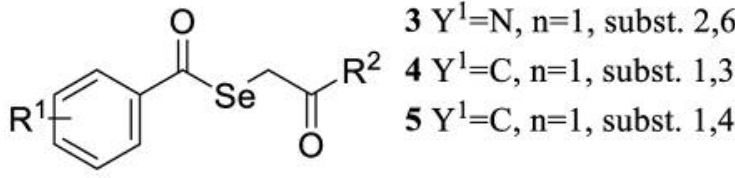

$6 \mathrm{R}^{1}=-\mathrm{H}, \quad \mathrm{R}^{2}=-\mathrm{NH}_{2}$

$7 \quad \mathrm{R}^{1}=4-\mathrm{Cl}, \quad \mathrm{R}^{2}=-\mathrm{OCH}_{3}$

$8 \mathrm{R}^{1}=-\mathrm{H}, \quad \mathrm{R}^{2}=-\mathrm{OPh}$

$9 \mathrm{R}^{1}=4-\mathrm{Cl}, \quad \mathrm{R}^{2}=-\mathrm{CH}_{3}$

$13 \mathrm{Y}^{2}=\mathrm{K}^{+}, \quad \mathrm{X}^{2}=\mathrm{OCN}^{-}$

$10 \mathrm{R}^{1}=4-\mathrm{Cl}, \quad \mathrm{R}^{2}=-\mathrm{C}\left(\mathrm{CH}_{3}\right)_{3}$

$11 \mathrm{R}^{1}=3,5-\mathrm{diOCH}_{3}, \mathrm{R}^{2}=-\mathrm{C}\left(\mathrm{CH}_{3}\right)_{3}$

$14 \mathrm{Y}^{2}=\mathrm{NH}_{4}^{+}, \mathrm{X}^{2}=\mathrm{SCN}^{-}$

$15 \mathrm{Y}^{2}=\mathrm{K}^{+}, \quad \mathrm{X}^{2}=\mathrm{SeCN}^{-}$

Cyanates

\section{Selenocompounds and reference chalcogens}

Promethazine<smiles>CCCN1c2ccccc2Sc2ccccc21</smiles><smiles>CN1CCCCC1</smiles>

Thioridazine<smiles>CCN1c2ccccc2Sc2ccc(SC)cc21</smiles>

\section{Chlorpromazine}

Figure 1. Structure of the Se-compounds (1-11), reference chalcogens (12-15) and phenothiazines evaluated in this study.

EX ELISA reader (Thermo Labsystems, Cheshire, WA, USA). Inhibition of the cell growth was determined according to the formula below:

$I_{50}=100-\left[\frac{\text { OD sample }-O D \text { medium control }}{\text { OD cell control }- \text { OD medium control }}\right] \times 100$

Checkerboard combination assay. A checkerboard microplate method was applied to study the effect of drug interactions between the Se-compounds (1-11), the reference chalcogens (12-15) and the phenothiazines (PMZ, CPZ and TZ). The assay was carried out using multidrug-resistant mouse T-lymphoma cells overexpressing the ABCB1 transporter (15). The dilutions of phenothiazines were made in the direction from left to right in $100 \mu \mathrm{l}$ (stock solutions and final concentrations used in the assay are presented in Table I), and the dilutions of the Se-compounds from the top to bottom in the microtiter plate in $50 \mu \mathrm{l}$ volume. The cells were re-suspended in culture medium and distributed into each well in $50 \mu$ l containing $6 \times 103$ cells. The cells were incubated for $72 \mathrm{~h}$. At the end of the incubation period the cell growth rate was determined by the MTT assay as described above. The combination index (CI) values at $50 \%$ of the growth inhibition dose $\left(\mathrm{ED}_{50}\right)$ were determined using CompuSyn software (ComboSyn, Inc., Paramus, NJ, USA) to plot four to five data points to each ratio (19). CI values were calculated by means of the median-effect equation, according to the ChouTalalay method, where $\mathrm{CI}<1, \mathrm{CI}=1$, and $\mathrm{CI}>1$ represent synergism, additive effect (or no interaction), and antagonism, respectively (19).
Table I. Cytotoxicity of the tested compounds against NIH/3T3 mouse embryonic fibroblast cells and selectivity indices (SI).

\begin{tabular}{lccc}
\hline & \multirow{2}{*}{$\begin{array}{c}\text { NIH/3T3 } \\
\mathrm{A}-\mathrm{IC}_{50} \\
(\mu \mathrm{M})\end{array}$} & $\mathrm{A} / \mathrm{B}(31)$ & $\mathrm{A} / \mathrm{C}(31)$ \\
\cline { 3 - 4 } & $>100$ & $\geq 25$ & $\geq 22$ \\
$\mathbf{1}$ & 23.7 & 0.24 & 0.24 \\
$\mathbf{2}$ & $>100$ & 5.1 & 5.9 \\
$\mathbf{3}$ & $>100$ & $\geq 1.0$ & $\geq 1.0$ \\
$\mathbf{4}$ & $>100$ & $\geq 1.0$ & $\geq 1.0$ \\
$\mathbf{5}$ & 69.7 & $\leq 0.70$ & $\leq 0.70$ \\
$\mathbf{6}$ & 23.7 & $\leq 0.24$ & $\leq 0.24$ \\
$\mathbf{7}$ & 74.5 & $\leq 0.75$ & $\leq 0.75$ \\
$\mathbf{8}$ & 0.62 & 0.81 & 0.60 \\
$\mathbf{9}$ & 1.35 & 1.44 & 3.14 \\
$\mathbf{1 0}$ & 0.82 & 0.63 & 0.85 \\
$\mathbf{1 1}$ & $>100$ & $\geq 1.0$ & $\geq 1.0$ \\
$\mathbf{1 2}$ & $>100$ & $\geq 1.0$ & $\geq 1.0$ \\
$\mathbf{1 3}$ & $>100$ & $\geq 1.0$ & $\geq 1.0$ \\
$\mathbf{1 4}$ & $>100$ & $\geq 1.0$ & $\geq 1.0$ \\
$\mathbf{1 5}$ & & &
\end{tabular}

PMZ: Promethazine; CPZ: chlorpromazine; TZ: thioridazine; $\mathrm{B}: \mathrm{IC}_{50}$ of the tested compounds against parental (PAR) mouse T-lymphoma cells (14); C: $\mathrm{IC}_{50}$ of tested compounds against multidrug resistant (MDR) mouse T-lymphoma cells (14); SI: Selectivity Index; SI $<1$ values denote lack of selectivity, $1<\mathrm{SI}<3$ mean a slight selectivity and $3<\mathrm{SI}<6$ values indicate moderate selectivity and are signalled with italics; whereas values of $\mathrm{SI}<6$ indicate that the compounds are strongly selective and are highlighted in bold $(14,19)$. 


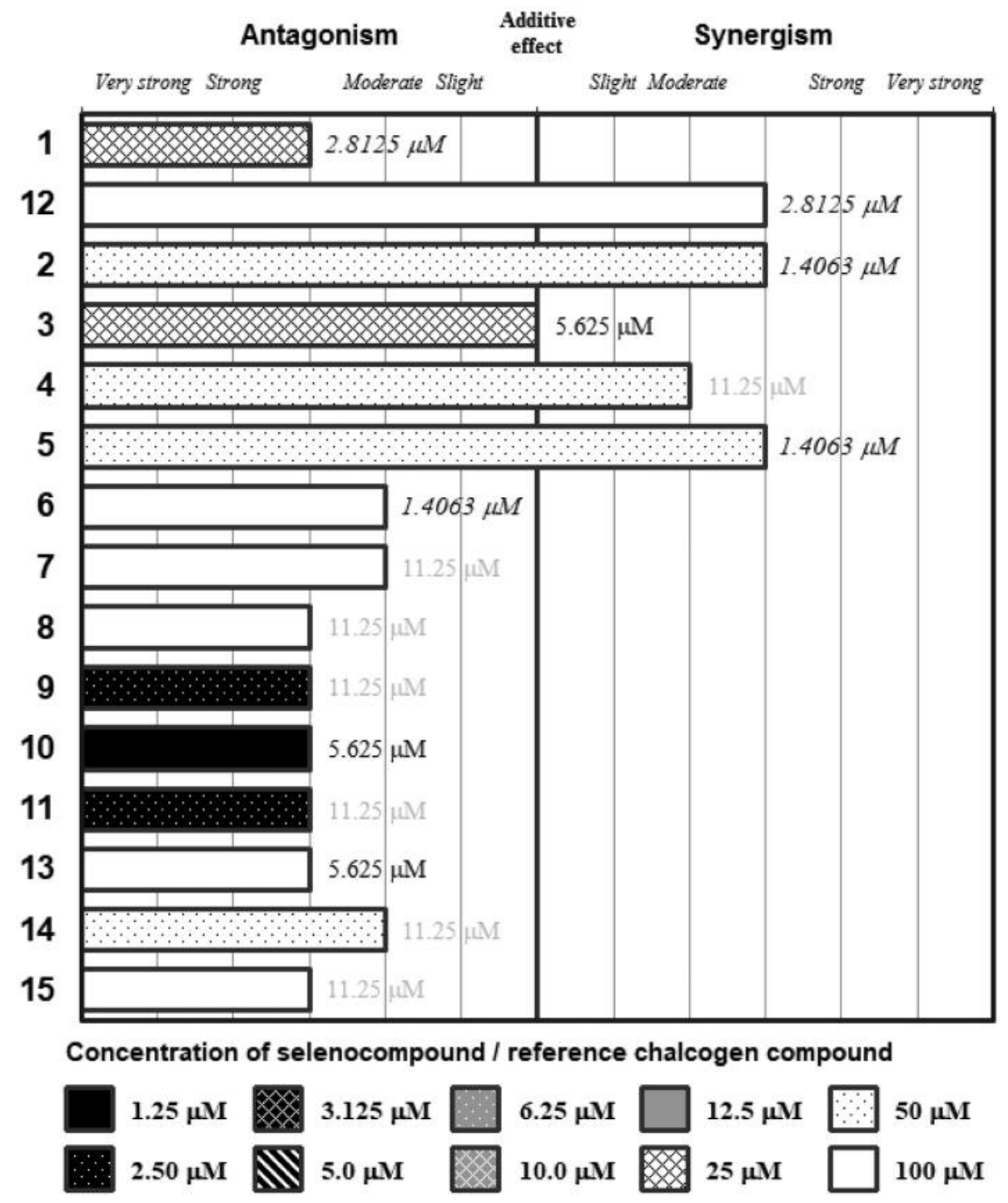

Figure 2. Interactions of the Se-compounds 1-11 and the reference chalcogens 12-15 with promethazine. The concentration of the tested (O/S/Se)compounds are presented below the graph, the concentration of promethazine is given inside graph (in bold: submicromolar concentration, in italics concentration between 1 and $5 \mu \mathrm{M}$, in plain text concentration between 5 and $10 \mu \mathrm{M}$, in grey concentration higher than $10 \mu \mathrm{M})$.

\section{Results}

The cytotoxic activity of the Se-compounds and the reference chalcogens has been previously determined on parental and multidrug resistant mouse T-lymphoma cells (17). The final concentration of the Se-compounds used in the combination experiments was chosen in accordance with our previous results, while the cytotoxicity of the phenothiazines was assessed before performing the checkerboard combination assay to determine their ideal concentrations for these experiments (the concentrations of the stock solutions used and the final concentrations are presented in Table I). Using the NIH/3T3 mouse embryonic fibroblast cell line, the toxicity on non-tumoral cells and the selectivity of the Se-compounds and phenothiazines was also assessed and the results were expressed in terms of the selectivity index (SI) values $(14,20)$. Out of the fifteen tested compounds, seven showed toxicity against the mouse embryonic fibroblasts (namely compounds 2, 6, 7, 8, 9, 10 and 11) at $100 \mu \mathrm{M}$ concentrations, while only three showed selectivity (compound 1: strongly selective, compounds 3 and 10: moderately selective) towards tumor cells, in agreement with our previous results on murine lymphoma cell lines (Table II) (14). 


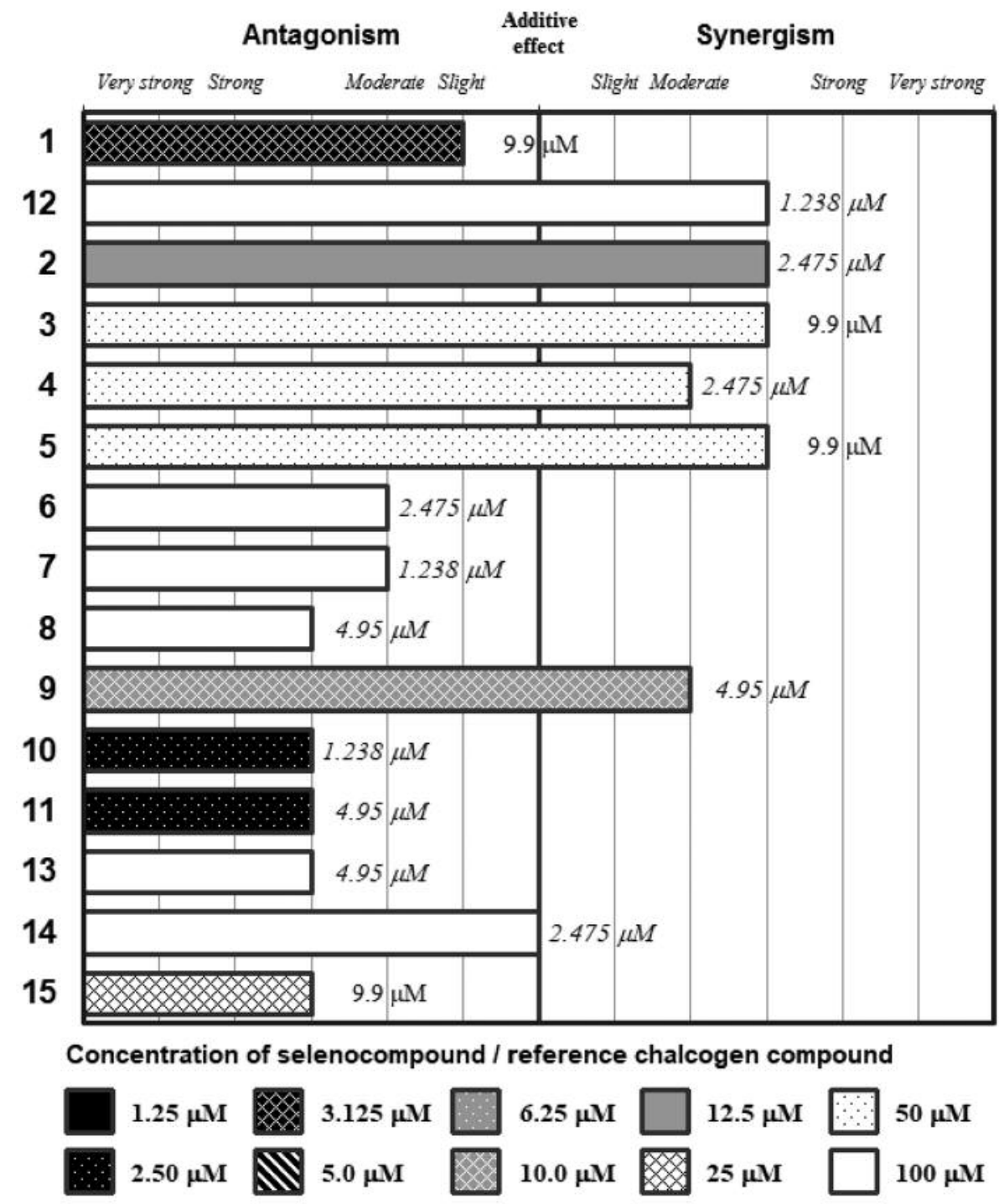

Figure 3. Interactions of the Se-compounds 1-11 and the reference chalcogens 12-15 with chlorpromazine. The concentration of the tested (O/S/Se)compounds are presented below the graph, the concentration of chlorpromazine is given inside graph (in bold: submicromolar concentration, in italics concentration between 1 and $5 \mu \mathrm{M}$, in plain text concentration between 5 and $10 \mu \mathrm{M}$, in grey concentration higher than $10 \mu \mathrm{M}$ ).

The results of the combination experiments of Secompounds and promethazine, chlorpromazine and thioridazine are shown in Figures 2, 3 and 4, respectively. In addition, the concentrations that showed the most beneficial interactions in these experiments are also highlighted. As a general rule, compounds 2-5 presented with the most advantageous interaction profile (i.e. the highest CI scores were observed). The compounds $\mathbf{2}$ and $\mathbf{5}$ showed synergism with all tested phenothiazines). This is further highlighted by the fact that these compounds showed synergism with the phenothiazines in low concentration ranges (1.46-11.25 $\mu \mathrm{M})$. In contrast, compounds $\mathbf{6 - 8}$, and the reference compounds 12-15 mainly exhibited antagonism with phenothiazines (Figures 2-4). The compounds with low $\mathrm{IC}_{50}$ values in the present study and previous reports $(\mathbf{1}, \mathbf{1 0}$ and 11) also showed additive or antagonistic interactions with the phenothiazines, with the exception of compound 9, presenting synergism with chlorpromazine and thioridazine (CI values=0.58-0.82). Comparison of the results between the different phenothiazines indicated a pronounced tendency for decrease for the majority of Se-compounds from promethazine to thioridazine, with CI values going as low as $\mathrm{CI}_{2}=0.276$ in the case of thioridazine (Figures 2-4). 


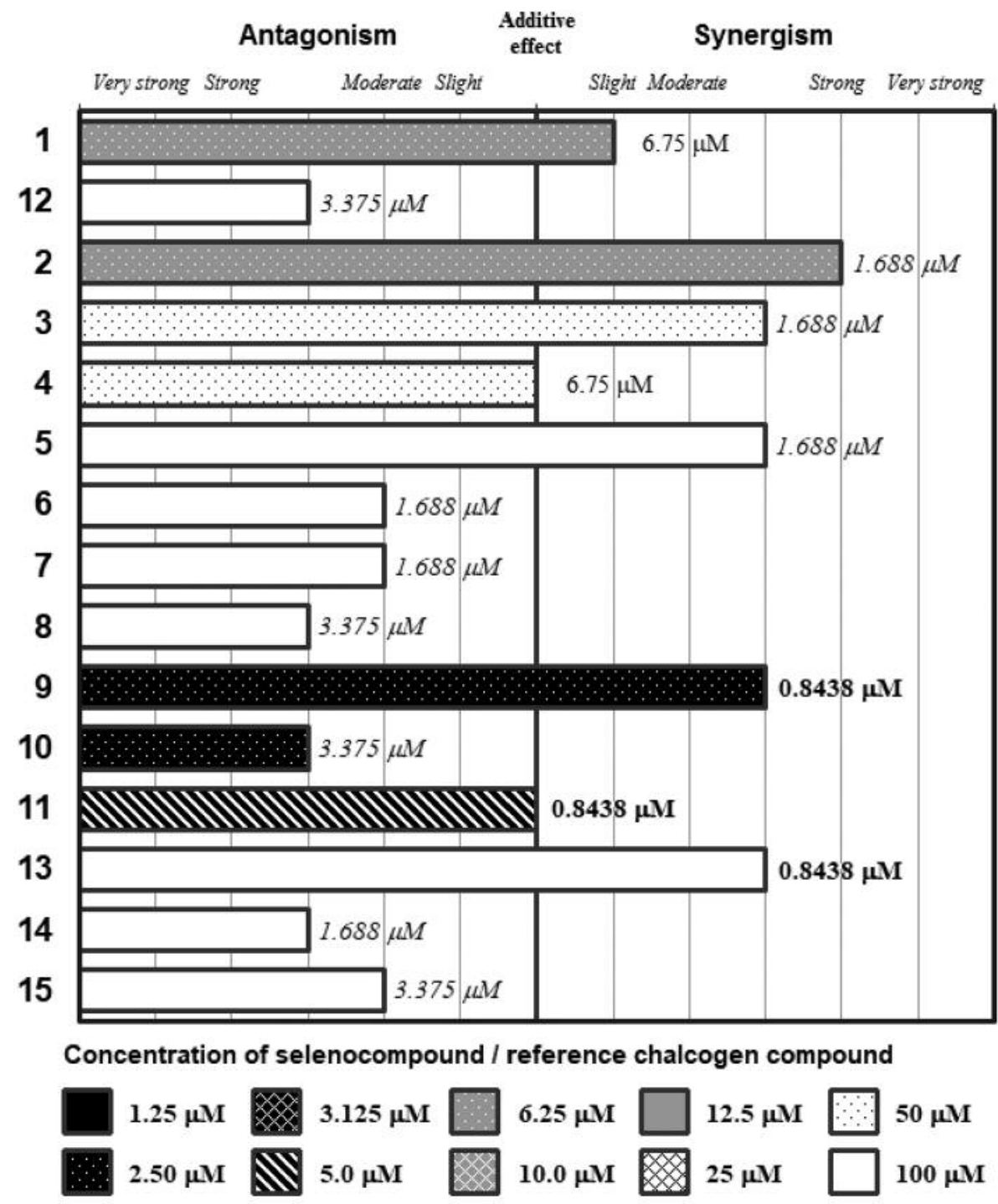

Figure 4. Interactions of the Se-compounds 1-11 and the reference chalcogens 12-15 with thioridazine. The concentration of the tested (O/S/Se)compounds are presented below the graph, the concentration of thioridazine is given inside graph (in bold: submicromolar concentration, in italics concentration between 1 and $5 \mu \mathrm{M}$, in plain text concentration between 5 and $10 \mu \mathrm{M}$, in grey concentration higher than $10 \mu \mathrm{M}$ ).

\section{Discussion}

The diversity of biological activities by phenothiazines and related compounds has been highlighted by numerous studies, both in psychopharmacology and in potentially novel therapeutic indications (1-5). The pleiotropy in their biological activities has also been shown in the case of their antipsychotic effects. For instance, they can act as nonselective antagonists of the dopamine receptor, serotonin receptors, histamine receptors, $\alpha$-adrenergic receptors and acetylcholine receptors (2). Certain phenothiazine compounds are currently used for the treatment of diseases: chlorpromazine as an antipsychotic drug (21); promethazine as antihistaminic; thioridazine as an antipsychotic, antitumor and antibacterial drug; trifluoperazine as a dopamine receptor-antagonist and methylene blue as an antioxidant and as a component of the therapy of cyanide intoxications and neurodegenerative diseases $(1,2,21)$.

The interest in Se-compounds as anticancer agents and adjuvants in chemotherapy has increased substantially in the last 15-20 years $(1-7,22)$. The activity of the present Secompounds in combination with a selection of chemotherapy drugs has been studied on a MDR mouse T-lymphoma cell line (23). It was found that the anticancer drugs that 
interacted in a more synergistic manner with these Secompounds were vincristine, doxorubicin, cyclophosphamide and methotrexate. In line to the results of this study, compounds 2-5 were shown to be highly effective adjuvants in very low concentrations (especially the thiophenederivative compound $\mathbf{2}$, showing strong synergism with all six tested chemotherapeutic drugs and verapamil). However, the cyclic selenoanhydride (1) and the methyl-ketone containing selenoesters (compounds 9-11) interacted synergistically or antagonistically with the anticancer drugs and phenothiazine evaluated.

In line with previous studies, the inorganic chalcogen salts and the O-isoster of compound $\mathbf{1}$ also showed no synergistic potential (23). In subsequent experiments in microbial model systems, it has been suggested that the biological activity of Se-compounds is dependent on their degradation into biologically-active species in the presence of oxygen; thus, their potential as anticancer adjuvants may also be mediated by a similar, yet unexplained mechanism (24).

Considering these results, phenothiazines have potential to be used as adjuvants in cancer chemotherapy. Our results suggest that phenothiazines with different chemical modifications showed different levels of adjuvant properties: thioridazine (a second-generation phenothiazine) showed lower CI values in a lower concentration range compared to promethazine and chlorpromazine (firstgeneration phenothiazines). However, the presence of the chlorine atom in position 2 of chlorpromazine was previously shown to enhance its biological activities, therefore it is unsurprising that these compounds showed more potent activity in our assays than the parental compound phenothiazine (4). The tested phenothiazines are all already approved medicines with known pharmacological and toxicity profiles, therefore, their use as adjuvants in cancer may be considered as a potential drug repurposing strategy. The synthesis of novel chemical compounds/libraries with phenothiazine-related structures and their biological screening as antitumor adjuvants may lead to potent lead compounds, capable of becoming relevant molecules for testing in animal experiments and human clinical trials.

\section{Conflicts of Interest}

The Authors have no conflicts of interest to declare regarding this study.

\section{Authors' Contributions}

G.S., E.D.A. and M.G. conceived and designed the study. M.G. and M.N. performed the laboratory work. M.G., B.V., Á.C., G.S., E.D.A. wrote the article and prepared the graphs and tables. C.S. and E.D.A. revised the manuscript critically. All Authors read and approved the final manuscript.

\section{Acknowledgements}

The study was supported by the Szeged Foundation for Cancer Research (Szegedi Rákkutatásért Alapítvány). M.N. was supported by EFOP 3.6.3-VEKOP-16-2017-00009. E.D.A. was supported by 'Iniciativas Ropelanas' and 'Asociación Cultural Trevinca', two associations from Zamora (Spain) that promote cancer research.

\section{References}

1 Ohlow MJ and Moosmann B: Phenothiazine: the seven lives of pharmacology's first lead structure. Drug Discov Today 16: 119131, 2011. PMID: 21237283. DOI: 10.1016/j.drudis.2011.01.001

2 Varga B, Csonka Á, Csonka A, Molnár J, Amaral L and Spengler G: Possible biological and clinical applications of phenothiazines. Anticancer Res 37: 5983-5993, 2017. PMID: 29061777. DOI: 10.21873 /anticanres.12045

3 Martins M, Dastidar SG, Fanning S, Kristiansen JE, Molnar J, Pagès JM, Schelz Z, Spengler G, Viveiros M and Amaral L: Potential role of non-antibiotics (helper compounds) in the treatment of multidrug-resistant Gram-negative infections: mechanisms for their direct and indirect activities. Int $\mathbf{J}$ Antimicrob Agents 31: 198-208, 2008. PMID: 18180147. DOI: 10.1016/j.ijantimicag.2007.10.025

4 Amaral L, Kristiansen JE, Viveiros M and Atouguia J: Activity of phenothiazines against antibiotic-resistant Mycobacterium tuberculosis: a review supporting further studies that may elucidate the potential use of thioridazine as anti-tuberculosis therapy. J Antimicrob Chemother 47: 505-511, 2001. PMID: 11328759. DOI: $10.1093 / \mathrm{jac} / 47.5 .505$

5 Takács D, Csonka Á, Horváth Á, Windt T, Gajdács M, Riedl Z, Hajós G, Amaral L, Molnár J and Spengler G: Reversal of ABCB1-related multidrug resistance of colonic adenocarcinoma cells by phenothiazines. Anticancer Res 35: 3245-3251, 2015. PMID: 26026084.

6 Ronald S, Awate S, Rath A, Carroll J, Galiano F, Dwyer D, Kleiner-Hancock H, Mathis JM, Vigod S and De Benedetti A: Phenothiazine inhibitors of TLKs affect double-strand break repair and DNA damage response recovery and potentiate tumor killing with radiomimetic therapy. Genes Cancer 4: 39-53, 2013. PMID: 23946870. DOI: 10.1177/1947601913479020

7 Spengler G, Molnar J, Viveiros M and Amaral L: Thioridazine induces apoptosis of multidrug-resistant mouse lymphoma cells transfected with the human ABCB1 and inhibits the expression of P-glycoprotein. Anticancer Res 31: 4201-4205, 2011. PMID: 22199281.

8 Jaszczyszyn A, Gąsiorowski K, Świątek P, Malinka W, CieślikBoczula K, Petrus J and Czarnik-Matusewicz B: Chemical structure of phenothiazines and their biological activity. Pharmacol Rep PR 64: 16-23, 2012. PMID: 22580516. DOI: 10.1016/s 1734-1140(12)70726-0

9 Kuršvietienė L, Mongirdienè A, Bernatonienė J, Šulinskienė J and Stanevičienè I: Selenium anticancer properties and impact on cellular redox status. Antioxidants 9: 80, 2020. PMID: 31963404. DOI: 10.3390/antiox9010080

10 Álvarez-Pérez M, Ali W, Marć MA, Handzlik J and DomínguezÁlvarez E: Selenides and diselenides: A review of their anticancer and chemopreventive activity. Molecules 23: 628, 2018. PMID: 29534447. DOI: 10.3390/molecules23030628 
11 Sakallı Çetin E, Nazıroğlu M, Çiğ B, Övey İS and Aslan Koşar $\mathrm{P}$ : Selenium potentiates the anticancer effect of cisplatin against oxidative stress and calcium ion signaling-induced intracellular toxicity in MCF-7 breast cancer cells: involvement of the TRPV1 channel. J Recept Signal Transduct Res 37: 84-93, 2017. PMID: 27055401. DOI: 10.3109/10799893.2016.1160931

12 Fan C, Zheng W, Fu X, Li X, Wong YS and Chen T: Strategy to enhance the therapeutic effect of doxorubicin in human hepatocellular carcinoma by selenocystine, a synergistic agent that regulates the ROS-mediated signaling. Oncotarget 5: 28532863, 2014. PMID: 24797310. DOI: 10.18632 /oncotarget.1854

13 Domínguez-Álvarez E, Plano D, Font M, Calvo A, Prior C, Jacob C, Palop JA and Sanmartín C: Synthesis and antiproliferative activity of novel selenoester derivatives. Eur J Med Chem 73: 153-166, 2014. PMID: 24389510. DOI: 10.1016/j.ejmech.2013.11.034

14 Gajdács M, Spengler G, Sanmartín C, Marć MA, Handzlik J and Domínguez-Álvarez E: Selenoesters and selenoanhydrides as novel multidrug resistance reversing agents: A confirmation study in a colon cancer MDR cell line. Bioorg Med Chem Lett 27: 797802, 2017. PMID: 28126516. DOI: 10.1016/j.bmcl.2017.01.033

15. Csonka A, Kincses, A, Nové M, Vadas Z, Sanmartín C, Domínguez-Álvarez E and Spengler G: Selenoesters and selenoanhydrides as novel agents against resistant breast cancer. Anticancer Res 39: 3777-3783, 2019. PMID: 31262904. DOI: 10.21873/anticanres.13526

16 Cornwell MM, Pastan I and Gottesman MM: Certain calcium channel blockers bind specifically to multidrug-resistant human $\mathrm{KB}$ carcinoma membrane vesicles and inhibit drug binding to $\mathrm{P}-$ glycoprotein. J Biol Chem 262: 2166-2170, 1987. PMID: 2434476.

17 Domínguez-Álvarez E, Gajdács M, Spengler G, Palop JA, Marć MA, Kieć-Kononowicz K, Amaral L, Molnár J, Jacob C, Handzlik J and Sanmartín C: Identification of selenocompounds with promising properties to reverse cancer multidrug resistance. Bioorg Med Chem Lett 26: 2821-2824, 2016. PMID: 27156771. DOI: $10.1016 /$ j.bmcl.2016.04.064
18 Bourichi S, Misbahi H, Rodi YK, Chahdi FO, Essassi EM, Szabó S, Szalontai B, Gajdács M, Molnár J and Spengler G: In vitro evaluation of the multidrug resistance reversing activity of novel imidazo[4,5-b]pyridine derivatives. Anticancer Res 38: 39994003, 2018. PMID: 29970523. DOI: 10.21873/anticanres. 12687

19 Chou T-C: Preclinical versus clinical drug combination studies. Leuk Lymphoma 49: 2059-2080, 2008. PMID: 19021049. DOI: 10.1080/10428190802353591

20 Acton EM, Narayanan VL, Risbood PA, Shoemaker RH, Vistica DT and Boyd MR: Anticancer specificity of some ellipticinium salts against human brain tumors in vitro. J Med Chem 37: 21852189, 1994. PMID: 8035425. DOI: 10.1021/jm00040a010

21 Dibben CRM, Khandaker GM, Underwood BR, O'Loughlin C, Keep C, Mann L and Jones PB: First-generation antipsychotics: not gone but forgotten. BJ Psych Bull 40: 93-96, 2016. PMID: 27087995. DOI: $10.1192 /$ pb.bp.115.050708

22 Grauman Neander N, Loner CA and Rotoli JM: The acute treatment of methemoglobinemia in pregnancy. J Emerg Med 54: 685-689, 2018. PMID: 29627348. DOI: 10.1016/j.jemermed.2018.01.038

23 Spengler G, Gajdács M, Marć MA, Domínguez-Álvarez E and Sanmartín C: Organoselenium compounds as novel adjuvants of chemotherapy drugs-a promising approach to fight cancer drug resistance. Molecules 24(2): 336, 2019. PMID: 30669343. DOI: $10.3390 /$ molecules 24020336

24 Spengler G, Kincses A, Mosolygó T, Marc MA, Nové M, Gajdács M, Marć MA, Sanmartín C, McNeil HE, Blair JMA, DomínguezÁlvarez E: Antiviral, antimicrobial and antibiofilm activity of selenoesters and selenoanhydrides. Molecules 24(23): 4264, 2019. PMID: 31771095. DOI: 10.3390/molecules24234264
Received March 16, 2020

Revised March 27, 2020

Accepted March 30, 2020 